\title{
Learning behavior of technical students - Awareness as key competence
}

\author{
Judith Klamert-Schmid ${ }^{1}$, Sabine Zangl ${ }^{1}$, Wolfgang Neussner ${ }^{1}$, Harald Lembacher ${ }^{1}$, Markus Lutz ${ }^{1}$, \\ Maximilian Lackner ${ }^{1, *}$
}

${ }^{1}$ FH Technikum Wien, Höchstädtplatz 6, 1200 Wien, Austria

*Corresponding author: maximilian.lackner@technikum-wien.at

\begin{abstract}
Learning has become more important than ever before, as we are moving towards a digital, fast-changing society. Formal university training has changed, too, from pure "lectures" to more modern formats, including e-learning, interactive and collaborative settings. Students also find plenty of information online, and the new skill in demand is finding relevant knowledge instead of having memorized knowledge. Knowledge doubles fast and becomes outdated even faster. Being aware of one's learning behaviors was found to be a core competence of university students eager to educate themselves. This work sets a self-assessment amongst bachelor and master students of a technical programme - International Business and Engineering - into perspective with literature findings. The authors conclude that knowing ones strengths in learning is a prerequisite of acquiring additional knowledge effectively and efficiency. Students have become more demanding towards the presentation of learning opportunities. However, it is them who have to take initiative to make most out of their learning journeys. As students progress through their studies, their awareness of collaborative and interactive learning seems to decrease, which reminds one of Socrates: "The more I know, the more I realize I know nothing. " One can speculate that his finding is due to more critical reflection by master students, or that by the time the students have entered the master's programme, the novel learning approaches have been familiarized/assimilated and do not receive further attention, which is a hint that the art of collaborative interactive learning has been mastered.
\end{abstract}

Keywords: university students, learning styles, awareness, collaborative learning, elearning, interactive learning, collaborative interactive learning

\section{Introduction}

"Learning is the process of acquiring new understanding, knowledge, behaviors, skills, values, attitudes, and preferences" [1]. Humans start learning at birth and continue with it throughout their lives. It can be done deliberately/consciously or without awareness. Learning can be triggered by an event, from playing, or it can be may in a formalized way, e.g. through university training. There is ample, ambiguous literature on learning styles and their significance. The literature describes more than 70 different learning styles [3]. 
One of the classic models is the one by David A. Kolb, which he had developed on experiential learning [4]. There are four approaches:

- Abstract Conceptualization,

- Active Experimentation,

- Concrete Experience,

- Reflective Observation

According to Kolb, the ideal learning process engages all four modes. It is individual preferences which result in 4 learning styles:

1. Accommodator $=$ Concrete Experience + Active Experiment: strong in "hands-on" practical doing (e.g., physical therapist)

2. Converger $=$ Abstract Conceptualization + Active Experiment: strong in practical "hands-on" application of theories (e.g., engineer)

3. Diverger $=$ Concrete Experience + Reflective Observation: strong in imaginative ability and discussion (e.g., social worker)

4. Assimilator $=$ Abstract Conceptualization + Reflective Observation: strong in inductive reasoning and creation of theories (e.g., philosopher) [4].

The model by Kolb was refined by Peter Honey \& Alan Mumford in their model [5]. They see 4 learning styles, which are more dependent on the situation rather than being personality traits:

1. Activist

2. Pragmatist

3. Reflector

4. Theorist

Burke Barbe et al. proposed three learning modalities (VAK):

1. Visualising modality

2. Auditory modality

3. Kinesthetic modality [6]

This model was refined by Neil Fleming to the VAK/VARK model [7]. That model shows four sensory modalities:

1. Visual learning

2. Auditory learning

3. Physical learning

4. Social learning

The model postulates multimodality in learners.

In multimedia learning, the learner deploys both auditory and visual stimuli for internalizing information [8].

Electronic learning (e-learning) is computer-enhanced learning. Here, one specific e-learning mode is mobile learning (m-learning), which uses different mobile telecommunication equipment, such as cellular phones/smartphones. Educational technology (EduTech, or EdTech) is the combined use of computer hardware and software to facilitate learning [9]. There is a plethora of tools available. Elearning can be synchronous or asynchronous. One can distinguish between linear learning and collaborative learning. The basic variant is computer-based training (CBT). Here, the learning is selfpaced and delivered through a computer or smartphone. The next stage is Computer-supported 
collaborative learning (CSCL) [10]. The most advances stage is mixed reality (virtual reality, VR, augmented reality, AR) [11].

\section{Modern university teaching}

In the $17^{\text {th }}$ century, when books were expensive, a classic "lecture" meant that a professor was reading out information to students [2]. That setting has changed, and the students' learning journey has become richer, by inclusion of other formats such as seminars, excursions, field trips, group work, etc. Universities of applied sciences focus on the immediate usefulness of the taught matter for the business world, so there is less theory than in classic universities. Students have become used to great animated videos, e.g. through youtube [12], and they expect a modern setting for their university training. Amongst modern learning methods, collaborative learning, interactive learning and their combination, collaborative interactive learning, deserve some scrutiny.

\section{Collaborative learning}

Teamwork is important for success of the individual in virtually all settings. "The true egotist collaborates - and so do all others. We have a strong believe that students do not compete against each other; There is no forced distribution of grades where someone has to lose for someone else to be able to win. In order to prepare students for collaboration in their work lives, collaborative learning [18] is an adequate tool. It can be organized in pairs of two or in lager groups. Peer-to-peer is an effective way. Advantages of collaborative learning are:

- Quality time with faculty/teachers

- Learning setting that is closer to real life

- Increased student interaction

- Development of vital skills, e.g. communication, thinking and self-management; And of course leadership.

\section{Interactive learning}

Interactive means that learning does not happen in a passive "teacher/student" setting, but learners are engaged. Common methods are discussions, group work and simulation games. Concepts include flipped classroom, E-learning and problem-based learning (PBL). Digital tools have facilitated interactive learning [19], [20]. One good example are massive open online course (MOOCs).

\section{Collaborative interactive learning}

"The field of collaborative interactive learning (CIL) aims at developing and investigating the technological foundations for a new generation of smart systems that support humans in their everyday life. While the concept of CIL has already been carved out in detail (including the fields of dedicated CIL and opportunistic CIL) and many research objectives have been stated, there is still the need to clarify some terms such as information, knowledge, and experience in the context of CIL and to differentiate CIL from recent and ongoing research in related fields such as active learning, collaborative learning, and others. [23]".

So while the term CIL is used in the IT sector [21], [22], in the context of university training it is the syntax of different tools and methods to make student learn in a highly engaging setting, to maximize the learning outcome. The university of applied Sciences FH Technikum Wien has embarked on a project of curricula modularization and standardization [24], [25], in order to offer students an up-todate studying experience. The 2 study programmes bachelor "International Business and Engineering" (BIW) and master "International Business and Engineering" (MIW) heavily rely on a mix of learning methods, where collaborative, interactive and collaborative interactive learning are practiced. The teaching is complemented by extracurricular activities such as study field trips and international projects. 
Also, students are encouraged and supported to participate in hackathons and summer schools, and a semester abroad, to broaden their exposure. Apart from faculty teachers, lecturers from the "outside world" are included in the teaching, with a fraction of approx. 20-30\%. This ensures that current knowledge from the business world is presented to students. "Expert talks" are a format where interesting speakers present topics to our students, followed by lively discussions. The ambition is to have "quality time" in the classroom; Students should have acquired factual knowledge before coming to class, so that the lecture can be used e.g. for discussions. Annual lecturers' meetings organized by the programme directorate ensure that courses are aligned and that lecturers all pull on one (virtual) rope so to speak. It must not be overlooked that since our students are mostly working apart from studying, they bring valuable knowledge and experience to class, too, from which their fellow students can benefit.

\section{On the relevance of adequate technical training}

With the amount of knowledge virtually exploding, the half-life of information keeps shortening. Practitioners need to keep learning and developing in order to keep pace with the modern world. As teachers, we need to prepare our students to solve real-world problems in the future - problems that do not yet exist and for which the tools and approaches are yet to be developed. What are the key " $21^{\text {st }}$ century skills" [13], [14], [15]? The following Fig. 1 shows a summary by P21. The P21 is the The Partnership for 21 st Century Skills, see [17].

\begin{tabular}{|l|c|c|}
\hline \multicolumn{1}{|c|}{ Learning and Innovation } & Digital Literacy & Career and Life \\
\hline Critical thinking \& problem solving & Information literacy & Flexibility \& adaptability \\
\hline Creativity and innovation & Media Literacy & Initiative \& self-direction \\
\hline Communication & ICT Literacy & Social \& cross-cultural interaction \\
\hline Collaboration & & Productivity \& Accountability \\
\hline & & Leadership \& responsibility \\
\hline
\end{tabular}

Fig. 1: P21 skills. ICT = information and communications technology. Source: [16]

As one can see from Fig. 1, learning has to involve collaboration and communication. "Digital literacy" is of utmost importance, too, just as is the maintenance of "employability", because the job world is so dynamic that every employee and/or entrepreneur needs to be able to adjust him-or herself to new situations fast.

Digitization has become a megatrend, and particularly technical studies (STEM: science, technology, engineering and mathematics) almost guarantee a job for graduates, since the demand for graduates is significantly higher than their number. Industrial engineering is no purely technical discipline; Our graduates work at the interface between technology and business, and this is a highly sought-after qualification; The industrial engineer virtually "translates" between the 2 worlds. In ever-increasing interdisciplinary and complex settings, it is this mix of competencies that makes industrial engineers very useful [26]. For graduates of purely technical degree programmes, adding a postgraduate legal or economic education, e.g. an LLM and MBA, can be a good choice. Our experience shows that it is in 
general easer for a technical graduate to acquire additional knowledge and competence in economics than the other way round. Technical training, with a graduation on BSc or even better on MSc level, is a valuable asset. The return on investment has always been highest for education, and this is still the case and will be in future. A formal university degree, however, is not enough (any more). One will need to keep learning throughout one's professional life, through various channels.

\section{Method}

The authors are teaching in industrial engineering in a bachelor and in a master programme, both of which are enrolled by part-time students. In this work, students from the $2^{\text {nd }}, 4^{\text {th }}$ and $6^{\text {th }}$ semester of the bachelor degree and students from the $2^{\text {nd }}$ and $4^{\text {th }}$ semester of the master degree were surveyed. They were asked to assess their own learning experience. In total, 161 students were included. Most of these students are from Austria, with some incomings from other countries $(<10 \%)$. They survey was carried out in April 2021 using the tool LimeSurvey. 45\% of all eligible students took part in the survey, which took less than 5 minutes to complete.

Work experience of the surveyed students ranged from none to 23 years, with the average being 3-7 years, see Fig. 2.

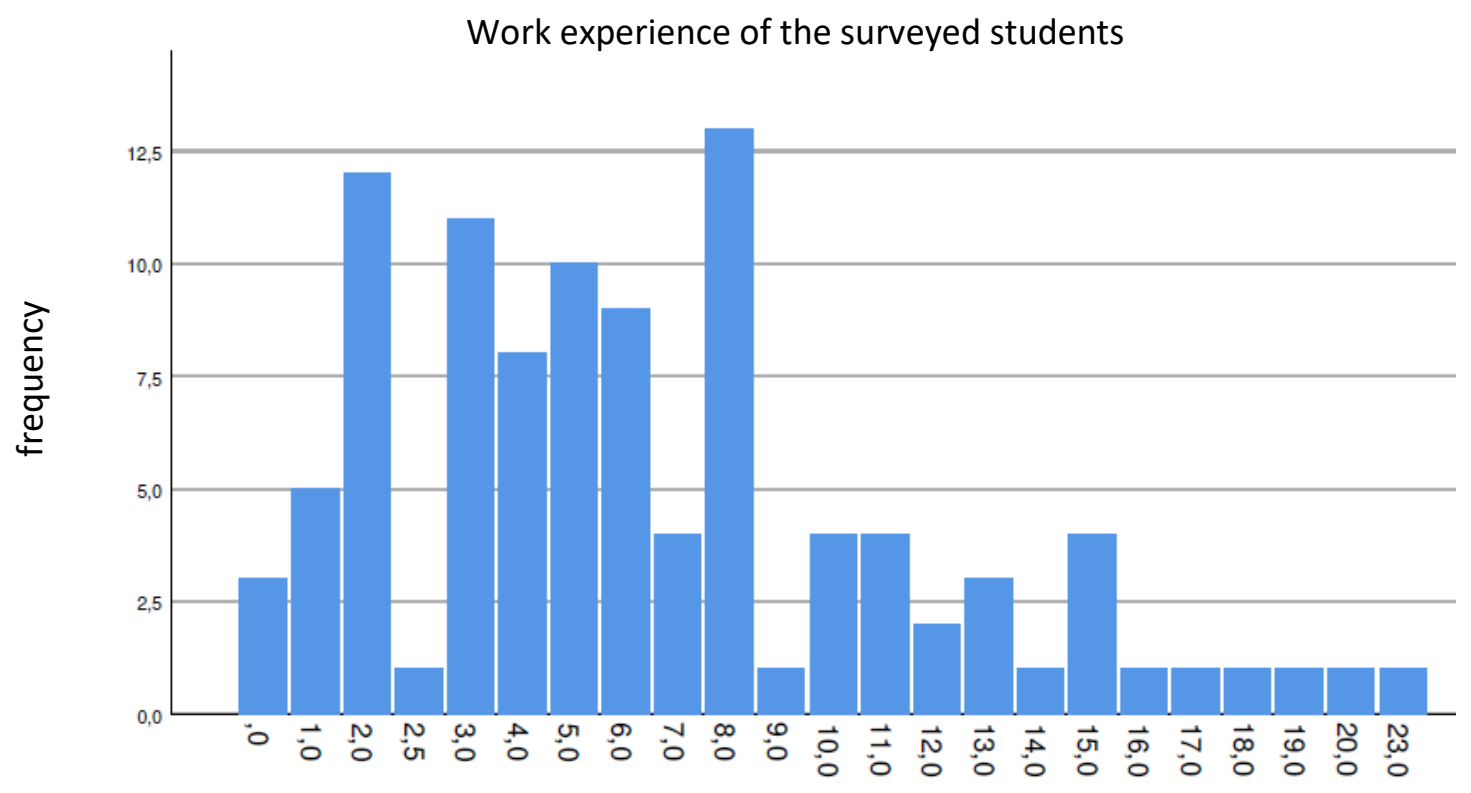

Fig. 2: Work experience of the surveyed students (both bachelor and master students).

An interesting finding was that $56 \%$ of the students already had leadership experience, which is significantly above the average (approx. $10 \%$ of all employees are managers), Fig. 3. 


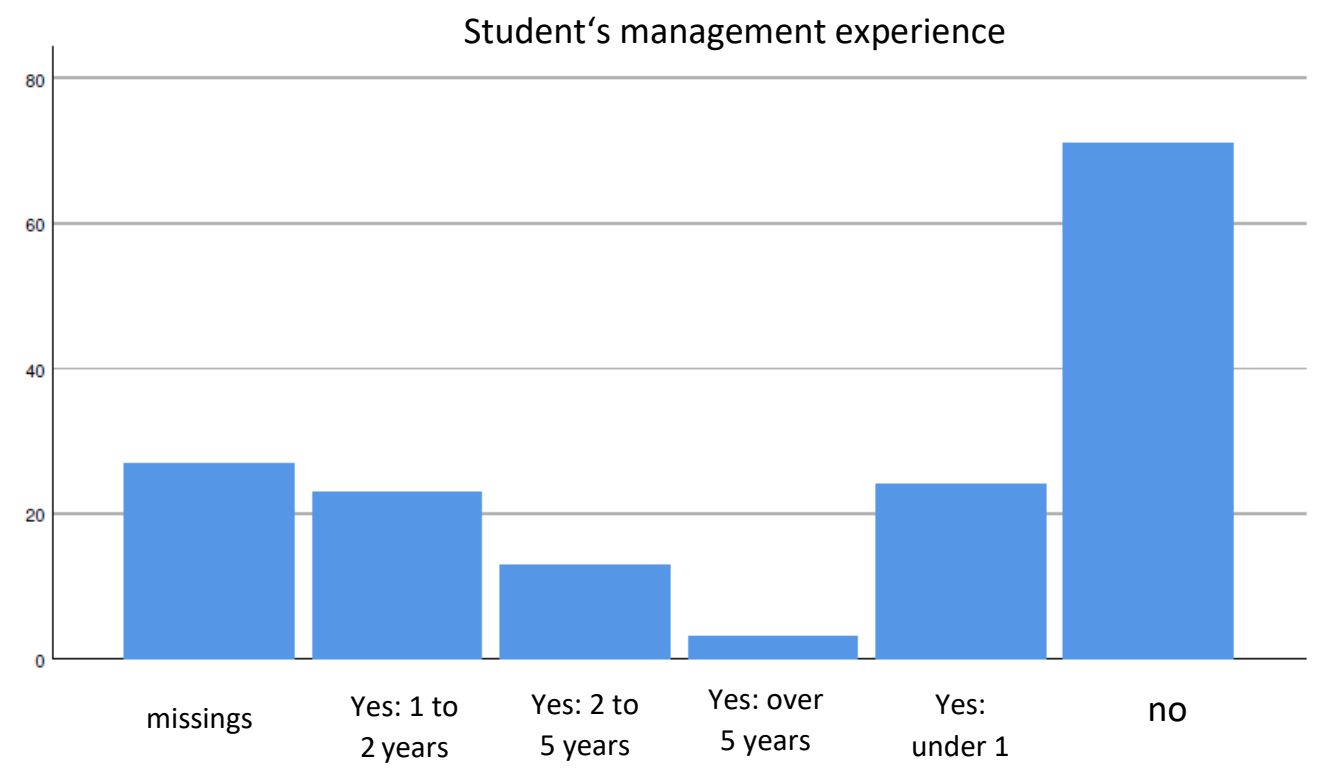

Fig. 3: Students's management experience. Only 44\% of all 161 respondents had no practical experience in a leadership setting.

Figures 4-8 show the main results of this work; Students were asked to rate, from 1 (= very much) to 5 (=not at all) their perception of 5 questions related to collaborative, interactive and collaborative interactive learning. 3 questions concerned their perceived knowledge about the terms per se, and 2 questions were about student's conception of personal experience, i.e. whether they recall having gone through such training.

To start with, most students have a clear understanding of collaborative and interactive learning, see Figs. 4-5.

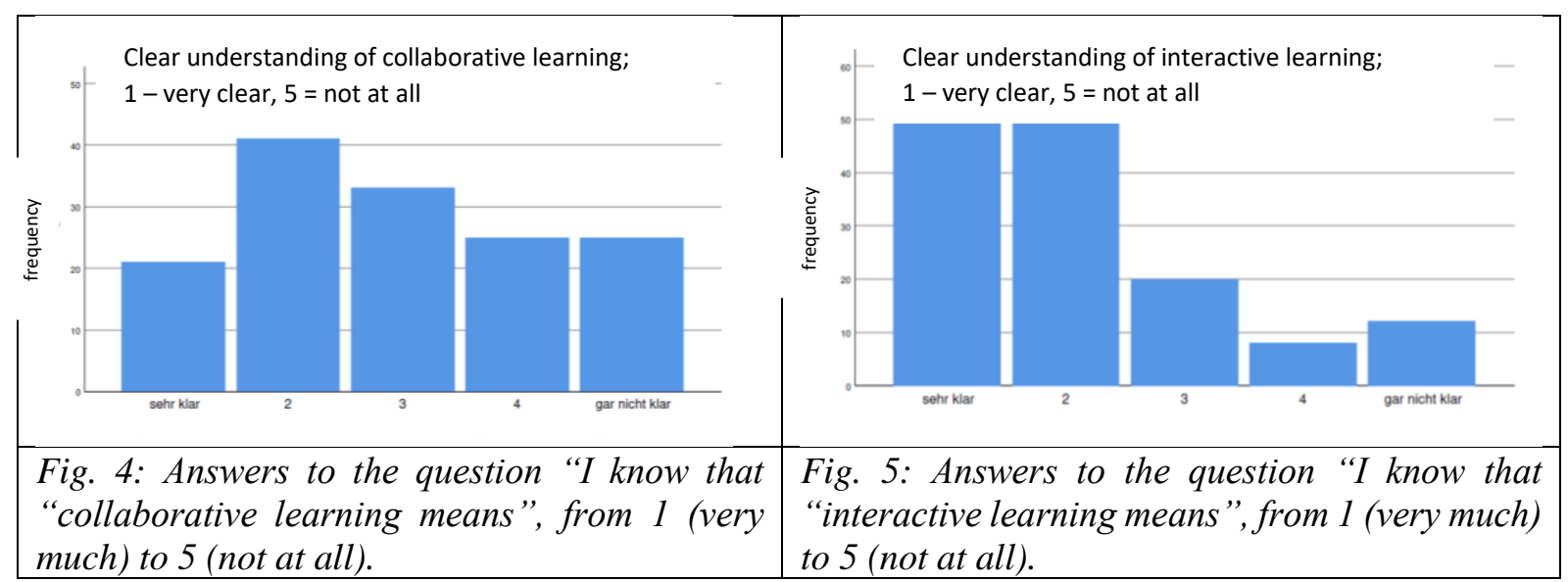

As Figs. 4 and 5 show, the term "interactive learning" is known (presumably) better than "collaborative learning". By contrast, must students are not very familiar with the term "collaborative interactive learning", see Fig. 6. 


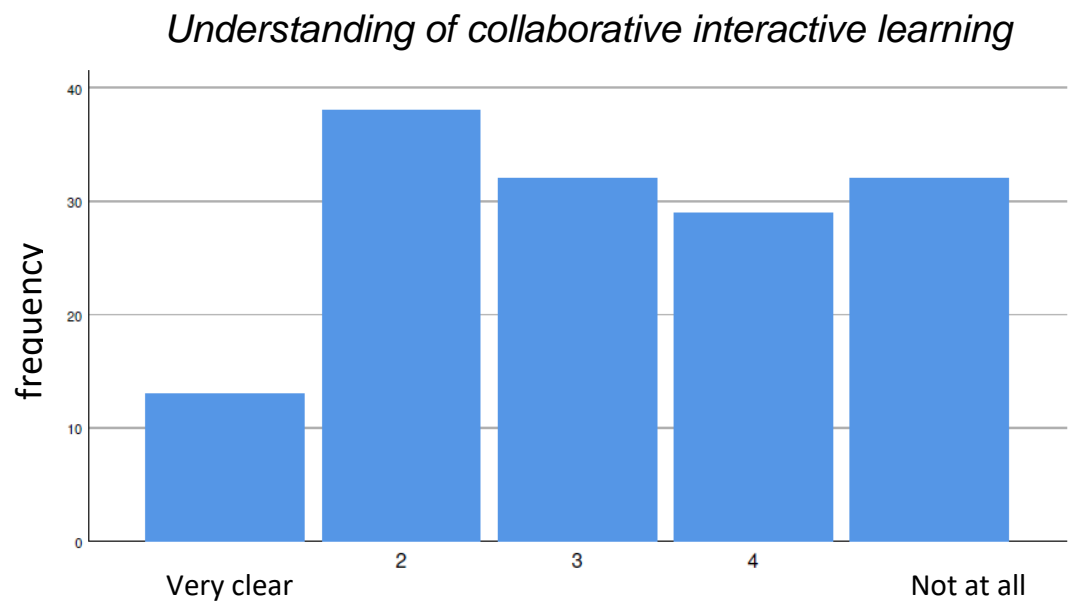

Fig. 6: Self-assessment by students whether they know what "collaborative interactive learning" means, from 1 (very much) to 5 (not at all).

Fig. 6 shows clearly that students are not so comfortable with the term, which is also less intuitive than the "basic" concepts of "collaborative learning" and "interactive learning" regarded separately.

In Fig. 7-8, students' perceived experience with collaborative learning (Fig. 7) and with interactive learning (Fig. 8) is depicted.

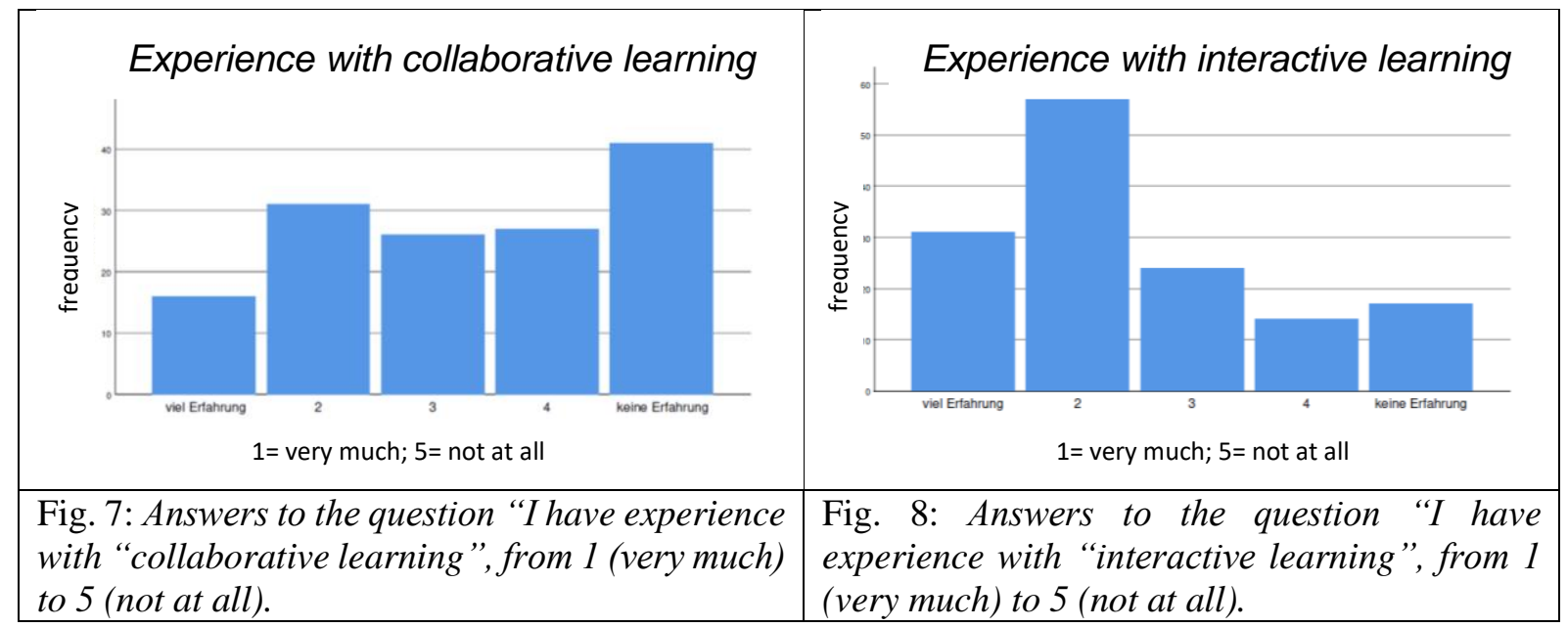

From Figs. 7 and 8, one can infer a "mixed" perception by students. Table 1 below shows the survey results by semester, bachelor (BIW) and master (MIW). 
Table 1: Survey results. Blue = average; red = below average; green = above average. Low numbers mean "high agreement" and larger numbers mean "low agreement". See text for details.

\begin{tabular}{|l|r|r|r|r|r|r|}
\hline & $\begin{array}{l}\text { Collaborative } \\
\text { learning: } \\
\text { Concept }\end{array}$ & $\begin{array}{l}\text { Interactive } \\
\text { learning: } \\
\text { Concept }\end{array}$ & $\begin{array}{l}\text { Collaborative } \\
\text { interactive } \\
\text { learning: } \\
\text { Concept }\end{array}$ & $\begin{array}{l}\text { Collaborative } \\
\text { learning: } \\
\text { Experience }\end{array}$ & $\begin{array}{l}\text { Ineractive } \\
\text { learning: } \\
\text { Experience }\end{array}$ & Average \\
\hline BIW, 2 Sem & 2.79 & 2.00 & 2.87 & 3.50 & 2.29 & 2.69 \\
\hline BIW, 4 Sem & 2.84 & 1.87 & 2.95 & 3.11 & 2.34 & 2.62 \\
\hline BIW, 6 Sem & 2.72 & 2.25 & 3.28 & 3.26 & 2.58 & 2.82 \\
\hline MIW, 2 Sem & 3.26 & 2.04 & 3.38 & 3.56 & 2.56 & 2.96 \\
\hline MIW, 4 Sem & 3.50 & 2.69 & 3.54 & 3.86 & 2.86 & 3.29 \\
\hline Total & $\mathbf{2 . 9 4}$ & $\mathbf{2 . 1 3}$ & $\mathbf{3 . 2 0}$ & $\mathbf{3 . 3 3}$ & $\mathbf{2 . 5 0}$ & $\mathbf{2 . 8 2}$ \\
\hline BIW & 2.78 & 2.05 & 3.07 & 3.24 & 2.43 & 2.71 \\
\hline MIW & 3.34 & 2.25 & 3.44 & 3.66 & 2.66 & 3.07 \\
\hline
\end{tabular}

As one can see from Table 1, bachelor students tend to answer with higher agreement (lower numbers) than master students (higher numbers). The difference is aggregated and highlighted in Fig. 9.

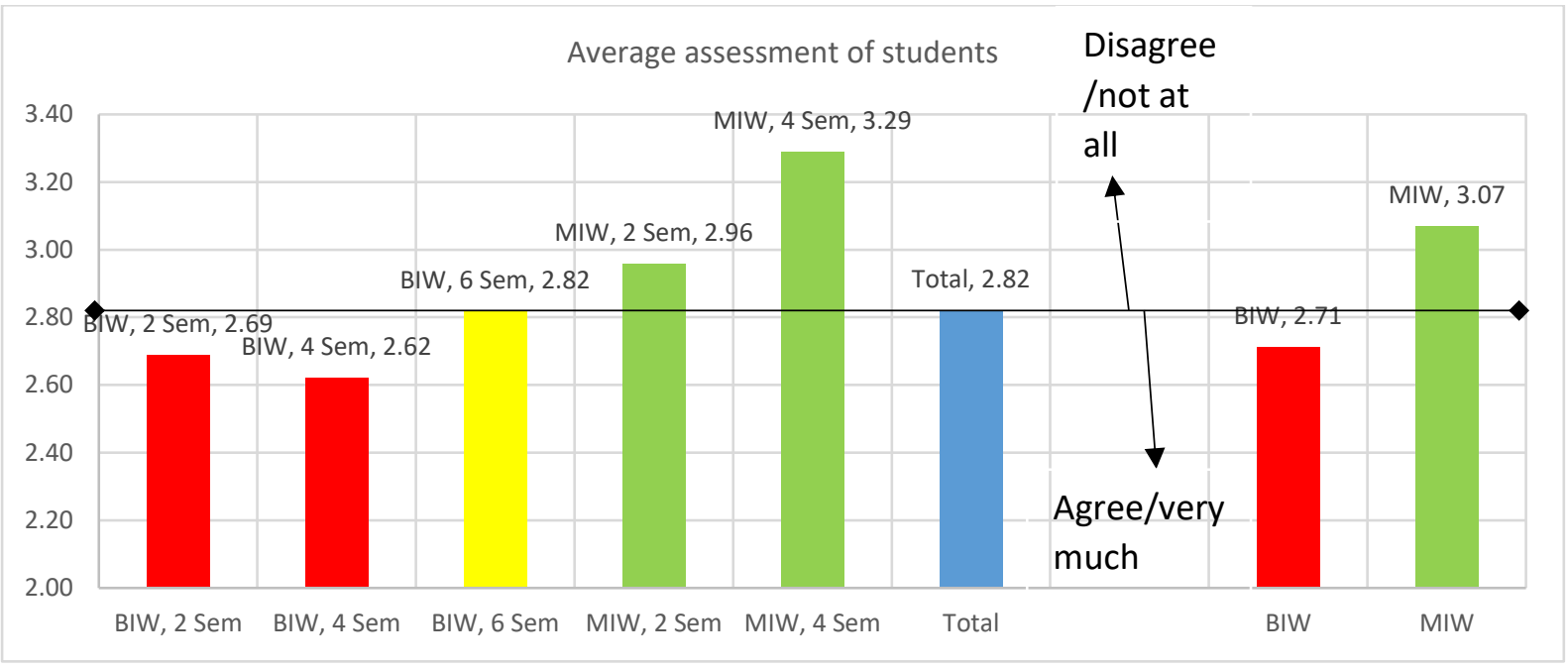

Fig. 9: "I know and have experience with the concepts of collaborative and/or interactive learning". I $=$ fully agree, $5=$ do not agree at all. See text for details.

Fig. 9 depicts clearly the results from Table 1. While bachelor students gain more confidence as they move from $2^{\text {nd }}$ to $4^{\text {th }}$ semester, on their way to and through the master programme their confidence towards the 2 tools gets less.

\section{Results and Discussion}

The results in Table 1 (Fig. 9) are somewhat puzzling. As the exposure of students to modern learning like collaborative, interactive and collaborative interactive increases from semester to semester, it is surprising to see that particularly the advanced master students have strong doubts. In fact, Fig. 9 shows an almost linear increase from bachelor $4^{\text {th }}$ semester to master $4^{\text {th }}$ semester. The root cause for this observation it not clear.

That outcome reminds one of Socrates: "The more I know, the more I realize I know nothing." One can speculate that his finding is due to more critical reflection by master students, or that by the time the 
students have entered the master's programme, the novel learning approaches have been familiarized/assimilated and do not receive further attention, which is a hint that the art of collaborative interactive learning has been mastered.

\section{Conclusion, Outlook}

From this study, it can be concluded that awareness about one's strengths and most effective learning approach is a critical competence in technical students.

Future work could address the correlation between learning success and learning approaches. Also, comparing skills amongst students from different universities, where a variety of teaching approaches is followed, could be interesting.

In [21], opportunistic collaborative interactive learning (OCIL) is discussed. This might become an interesting future area of research.

\section{Acknowledgements}

The authors want to thank their students for participation in this study. Despite a short time window for answering the questionnaire, $45 \%$ of all students took part. The ratio of female to make study participants matches the gender ratio in the 2 study programmes.

\section{References}

[1] Richard Gross, Psychology: The Science of Mind and Behaviour, Hachette, UK, ISBN: 978-14441-6436-7.

[2] Florian Eckkrammer, University of Applied Sciences Technikum Wien, Austria, private communication, 2021.

[3] Coffield, Frank; Moseley, David; Hall, Elaine; Ecclestone, Kathryn (2004). Learning styles and pedagogy in post-16 learning: a systematic and critical review (PDF). London: Learning and Skills Research Centre. ISBN 1853389188.

[4] Kolb, David A. (2015) [1984]. Experiential learning: experience as the source of learning and development (2nd ed.). Upper Saddle River, NJ: Pearson Education. ISBN 9780133892406.

[5] Honey, Peter; Mumford, Alan (2006). Learning styles questionnaire: 80-item version. London: Maidenhead. ISBN 1902899296.

[6] Barbe, Walter Burke; Milone, Michael N. (February 1981). "What we know about modality strengths" (PDF). Educational Leadership. Association for Supervision and Curriculum Development: 378-380.

[7] Fleming, Neil D. (2014). "The VARK modalities". vark-learn.com.

[8] Mayer, R. E., \& Moreno, R., "Nine ways to reduce cognitive load in multimedia learning." Educational psychologist, 38(1), 43-52, 2003.

[9] Robinson, Rhonda; Molenda, Michael; Rezabek, Landra. "Facilitating Learning" (PDF). Association for Educational Communications and Technology. Retrieved 18 March 2016.

[10] Robyn M. Gillies, Adrian Ashman, Jan Terwel, The Teacher's Role in Implementing Cooperative Learning in the Classroom (Computer-Supported Collaborative Learning Series), Springer, 2010 
[11] Horst Orsolits, Maximilian Lackner (editors), Virtual Reality und Augmented Reality in der Digitalen Produktion, Springer Gabler 2020.

[12] Deema MAHASNEH, Noordeen SHOQIRAT, Miranda Hawks, "From the classroom to Dr. YouTube": nursing students' experiences of learning and teaching styles in Jordan, Teaching and Learning in Nursing, 15 October 2020, Volume 16, Issue 1, Pages 5-9

[13] Chris Dede, Comparing Frameworks for " $21^{\text {st }}$ Century Skills", http://sttechnology.pbworks.com/f/Dede_(2010)_Comparing\%20Frameworks\%20for\%2021st\%20Cen tury\%20Skills.pdf, 2009; Accessed May 1, 2021

[14] https://www.battelleforkids.org/networks/p21/frameworks-resources; Accessed May 1, 2021

[15] https://www.oecd.org/site/educeri21st/40756908.pdf; Accessed May 1, 2021

[16] https://en.wikipedia.org/wiki/21st_century_skills\#/media/File:P21_Skills.jpg; Accessed May 1, 2021

[17] https://files.eric.ed.gov/fulltext/ED519462.pdf; Accessed May 1, 2021

[18] Edda Luzzatto, Giordano Dimarco, Collaborative Learning: Methodology, Types of Interactions and Techniques (Education in a Competitive and Globalizing World), Nova Science Pub Inc, 2009

[19] Doug Buehl, Classroom strategy for interactive learning, International Reading Association, 2013

[20] Kirsi VIRRANTAUS, INTERACTIVE LEARNING IN THE CLASSROOM - NOT A COMPETITOR BUT A PARTNER FOR E-LEARNING,

https://www.fig.net/resources/proceedings/fig proceedings/korea/fullpapers/pdf/session15/virrantaus.pdf,

[21] Bahle, Gernot, Calma, Adrian, Leimeister, Jan Marco, Lukowicz, Paul, Oeste-Reiss, Sarah, Reitmaier, Tobias, Schmidt, Albrecht, Sick, Bernhard, Stumme, Gerd, Zweig, Katharina Anna, [IEEE 2016 IEEE International Conference on Autonomic Computing (ICAC) - Wuerzburg, Germany (2016.7.17-2016.7.22)] 2016 IEEE International Conference on Autonomic Computing (ICAC) Lifelong Learning and Collaboration of Smart Technical Systems in Open-Ended Environments -Opportunistic Collaborative Interactive Learning, 2016

[22] Sick, Bernhard, Oeste-Reiß, Sarah, Schmidt, Albrecht, Tomforde, Sven, Zweig, Anna Katharina, Collaborative Interactive Learning, Informatik-Spektrum, 2018

[23] Tom Hanika, Marek Herde, Jochen Kuhn, Jan Marco Leimeister, Paul Lukowicz, Sarah OesteReiß, Albrecht Schmidt, Bernhard Sick, Gerd Stumme, Sven Tomforde, Katharina Anna Zweig, Collaborative Interactive Learning -- A clarification of terms and a differentiation from other research fields, https://arxiv.org/abs/1905.07264

[24] https://www.technikum-wien.at/newsroom/news/workshops-als-auftakt-zur-qualitaetssicherungder-lehre/

[25] https://www.ots.at/presseaussendung/OTS_20200603_OTS0068/bachelor-20-an-der-fhtechnikum-wien

[26] Zangl, Sabine, Klamert-Schmid, Judith, Lackner, Maximilian (editors), Berufsfeld Wirtschaftsingenieure: Die Vielfalt der Schnittstellenkompetenz, ISBN 978-3-658-32620-3, Springer Gabler, 2021 